\title{
A IMPORTÂNCIA DA ESCOLA INCLUSIVA PARA O DESENVOLVIMENTO DOS ESTUDANTES PÚBLICO-ALVO DA EDUCAÇÃO ESPECIAL
}

Daniela Carvalho dos Santos, Pâmela de Albuquerque Voltarelli, Danielle Aparecida do Nascimento dos Santos.

Universidade do Oeste Paulista - UNOESTE, Curso de Licenciatura em Pedagogia - FACLEPP, Presidente Prudente/SP. Email: danielle@unoeste.br

\section{RESUMO}

A educação inclusiva tem sido pauta de pesquisas, projetos, documentos e debates em diferentes áreas. Nos últimos anos, especialmente com a publicação da Política Nacional de Educação Especial na perspectiva da Educação Inclusiva no ano de 2008, passou-se a discutir a importância da constituição de escolas inclusivas para o atendimento e acesso dos Estudantes Público-Alvo da Educação Especial (EPAEE). Diante disso, neste trabalho será realizada uma reflexão no sentido de pensar qual é o papel da escola no desenvolvimento dos EPAEE e que tipo de apoio a escola deve oferecer para esses estudantes. O estudo é de natureza qualitativa do tipo documental e bibliográfica. Será abordado, entre outros aspectos, a necessidade de apresentar qual deve ser o papel da escola regular na promoção de estratégias que legitimem a inclusão de EPAEE.

Palavras-chave: Educação Inclusiva, Público-Alvo da Educação Especial, Papel da Escola.

\section{INCLUSIVE SCHOOL IMPORTANCE OF DEVELOPMENT OF TARGET STUDENTS OF SPECIAL EDUCATION}

\begin{abstract}
Inclusive education has been the agenda of research, projects, documents and discussions in different areas. In recent years, especially with the publication of the National Policy on Special Education from the perspective of Inclusive Education in 2008, we began to discuss the importance of the establishment of inclusive schools for the service and access Target audience of Special Education Students. Therefore, in this work there will be a reflection on the sense of thinking what is the school's role in the development of the Students and what kind of support the school must offer to these students. The study is of a qualitative nature of the documentary and bibliographical. Will be addressed, inter alia, the need to present what should be the role of regular schools in promoting strategies to legitimize the inclusion of Special Education Students.

Keywords: Inclusive Education, Target audience of Special Education, School.
\end{abstract}




\section{INTRODUÇÃO}

Os debates sobre a constituição de uma escola inclusiva são muito presentes na atualidade. Diante disso, são necessárias pesquisas que identifiquem aspectos da escola inclusiva que tem auxiliado na formação de estudantes com deficiências, transtornos globais do desenvolvimento e altas habilidades/superdotação, caracterizados pela Política Nacional de Educação Especial na perspectiva da Educação Inclusiva (2008) como Estudantes Público-Alvo da Educação Especial (EPAEE).

De acordo com as legislações vigentes, esses estudantes devem ser incluídos nas classes comuns das escolas regulares. Segundo o art. 3ํㅡ, inciso IV, a Declaração de Salamanca (1994) descreve:

[...] todas as escolas deveriam acomodar todas as crianças, independentemente de suas condições físicas, intelectuais, sociais, emocionais, linguísticas ou outras. Deveriam incluir todas as crianças deficientes e superdotadas, crianças de rua e que trabalham, crianças de origem remota ou população nômade, crianças pertencentes a minoria linguísticas, étnicas ou culturais e crianças de outros grupos em desvantagem ou marginalizados. As escolas têm que encontrar a maneira de educar com êxito todas as crianças, inclusive as que tem deficiências graves.

A escola como espaço social, ao reconhecer esses direitos, provoca mudanças em todo o seu sistema, especialmente nas práticas pedagógicas, que passam a ter a necessidade de incluir todos os estudantes. Segundo Figueiredo (2002, p.68),

Efetivar a inclusão, é preciso (...) transformar a escola, começando por desconstruir praticas segregacionistas. (...) a inclusão significa um avanço educacional com importantes repercussões políticas e sociais, visto que não se trata de adequar, mas de transformar a realidade das práticas educacionais.

Portanto, a escola tem papel fundamental no desenvolvimento dos EPAEE, e com isso deve levar em conta a formação dos professores e de toda a equipe escolar, assim como deve rever suas estruturas, organização, acessibilidade, Projeto Político-Pedagógico (PPP), recursos didáticos, metodologias e estratégias de ensino, e inclusive práticas avaliativas, com o intuito de aprimorar as possibilidades de aprendizagem de todos os estudantes.

A inclusão escolar busca transformar as escolas, tornando-as em espaços de formação e de ensino de qualidade para todos. Segundo a Constituição Federal Brasileira de 1988, o acesso ao ensino regular deve ser oferecido para todas as crianças e adolescentes. No caso dos EPAEE, devem receber um Atendimento Educacional Especializado (AEE) complementar ou suplementar, preferencialmente nas instituições de ensino.

Para isso, faz-se necessária a reestruturação das escolas, com apoios pedagógicos aprimorados. Segundo Camacho $(2003$, p.9) as mudanças têm como propósito

Estabelecer um tipo de escola capaz de adaptar-se, acolher e cultivar as diferenças como um elemento de valor positivo, e a abertura de um espaço pluralista e multicultural, no qual se mesclam as cores, os gêneros, as capacidades, permitindo assim o acesso a uma escola, uma educação, na qual todos, sem exclusão, encontrem uma resposta educativa de acordo com as suas necessidades e características peculiares.

Não há dúvida que, nesse contexto, a escola torna-se um sistema de suporte permanente e afetivo para os EPAEE, pois o AEE não é um sistema educacional paralelo, mas um conjunto de 
estratégias e recursos que a escola regular deverá dispor para atender os estudantes. Para tanto, a escola precisa incluir socialmente aqueles que vêm sendo excluídos.

Um dos desafios da constituição de uma educação inclusiva consiste em romper com o preconceito, uma vez que a educação na nossa sociedade é baseada na ideia de que todos são iguais, e devem ser tratados iguais. Portanto, algumas escolas ainda não criam espaços para que as crianças demonstrem suas habilidades e potencial.

É preciso repensar essa postura e questionar até que ponto a escola está conduzindo a formação da criança, precisamos de uma educação que respeite os direitos e promova a equidade, visando o respeito as diferenças, Segundo Baptista (2006, p.91)

A educação desse movimento mostra uma tendência que mantém e atualiza princípios norteadores de uma educação "ampla", propondo a inclusão escolar, cujos pontos fundamentais seriam uma ampliação dos sujeitos inseridos em contextos comuns de ensino e a necessária transformação da escola e das alternativas educacionais, no sentido de promover a educação dos alunos em geral.

O conceito de Educação Inclusiva surgiu ao longo dos anos 90, com os avanços provocados por dois encontros internacionais: a Conferência Mundial de Educação Para Todos, realizada em Jomtiem, na Tailândia, em 1900, e a Conferência Mundial de Educação Especial, realizada em 1994, em Salamanca, na Espanha.

A educação inclusiva caracteriza-se como um novo princípio educacional. As escolas inclusivas propõem um modo de constituir o sistema educacional que considera as especificidades de todos os estudantes, oferecendo um ensino que desenvolva suas habilidades e potencialidades Para que a inclusão se concretize e necessário repensar a forma com que as escolas estão sendo organizadas e colocar em prática o princípio de educação para todos.

Diante do exposto, o artigo versa sobre os aspectos da Educação Especial como serviço de apoio à educação inclusiva de EPAEE na escola regular. Por sua vez, traz uma discussão sobre o papel da escola e os tipos de apoio que as instituições de ensino oferecem às crianças, pesquisando a legislação que norteia a educação inclusiva e verificando as formas de igualdade no ensino.

\section{METODOLOGIA}

A abordagem para o desenvolvimento da pesquisa é a qualitativa do tipo documental e bibliográfica. A metodologia utilizada será a pesquisa bibliográfica por ser um procedimento que implica na leitura e análise de textos relevantes sobre o que se desejar estudar. Na concepção de Oliveira $(2008 p, 69)$

A principal finalidade da pesquisa bibliográfica é levar o pesquisador (a) a entrar em contato direto com obras, artigos ou documentos que tratem do tema em estudo. O mais importante para quem faz opção por uma pesquisa bibliográfica é ter a certeza de que as fontes a serem pesquisadas já são reconhecidamente do domínio cientifico.

A abordagem da pesquisa é qualitativa, buscando a elaboração de estratégias de ação que favoreçam a execução da proposta de inclusão escolar, tendo como principal fundamento a relação entre a inclusão e o objeto de estudo a escola regular. Sobre a abordagem qualitativa, Oliveira (2008, p. 60) enfatiza que:

A pesquisa qualitativa pode ser caracterizada como sendo um estudo detalhado de um determinado fato, objeto, grupo de pessoas ou ator social e fenômenos da realidade. Esse procedimento visa buscar informações fidedignas para se explicar em profundidade o significado e as 
características de cada contexto em que encontra o objeto de pesquisa. Os dados podem ser obtidos através de uma pesquisa bibliográfica, entrevistas, questionários, planilhas e todo instrumento (técnica) que se faz necessário para obtenção de informações.

Por fim é utilizado o método dialético, em uma perspectiva de entender e explicar a realidade dos EPAEE tendo como fonte de dados os documentos legais e artigos publicados sobre o tema.

\section{RESULTADOS}

Todos os seres humanos nascem livres e são iguais em dignidade e direitos (Declaração Universal dos Direitos Humanos, artigo 1ㅇ). Baseado nesse fundamento afirma que esse processo de inclusão escolar deve ser sustentado e garantido. De acordo com o Congresso Internacional Sociedade Inclusiva

O acesso igualitário a todos os espaços da vida é um pré-requisito para os direitos humanos universais e as liberdades fundamentais das pessoas. $\mathrm{O}$ esforço rumo a uma sociedade inclusiva para todos é a essência do desenvolvimento social sustentável (Declaração Internacional de Montreal sobre Inclusão, 2001).

Além desse documento legal, outros afirmam a importância da constituição de espaços inclusivos, dentre eles: Declaração Universal dos Direitos Humanos; Declaração Mundial Sobre Educação para Todos, Declaração de Salamanca; Convenção da Guatemala e a Declaração Internacional de Montreal.

Desde a Constituição da República Federativa do Brasil 1988, no artigo 206, inciso I, estabelece a "igualdade de condições de acesso e permanência na escola" como um dos princípios para o ensino e garante, como dever do Estado, a oferta do atendimento educacional especializado, preferencialmente na rede regular de ensino (art. 208). A Lei no 7.853/89 "[...] Define como crime recusar, suspender, adiar, cancelar ou extinguir a matrícula de um estudante por causa de sua deficiência, em qualquer curso ou nível de ensino [...]".

O Estatuto da Criança e do Adolescente - Lei no. 8.069/90 O artigo 55 reforça os dispositivos legais supracitados ao determinar que "os pais ou responsáveis têm a obrigação de matricular seus filhos ou pupilos na rede regular de ensino". A Política Nacional de Educação Especial 1994 acesso às classes comuns do ensino regular àqueles que "(...) possuem condições de acompanhar e desenvolver as atividades curriculares programadas do ensino comum, no mesmo ritmo que os alunos ditos normais".

A Lei de Diretrizes e Bases da Educação Nacional - Lei no 9.394/96 artigo 59, preconiza que os sistemas de ensino devem assegurar aos alunos currículo, métodos, recursos e organização específicos para atender às suas necessidades; assegura a terminalidade específica àqueles que não atingiram o nível exigido para a conclusão do ensino fundamental em virtude de suas deficiências e; a aceleração de estudos aos superdotados para conclusão do programa escolar.

As Diretrizes Nacionais para a Educação Especial na Educação Básica (Resolução CNE/CEB no 2/2001) artigo 20 Determinam que os sistemas de ensino devem matricular todos os alunos, cabendo às escolas organizarem-se para o atendimento aos educandos com necessidades educacionais especiais.

A Cartilha - O Acesso de Alunos com Deficiência às Escolas e Classes Comuns da Rede Regular 2004 O Ministério Público Federal divulga o documento com o objetivo de disseminar os conceitos e diretrizes mundiais para a inclusão; Plano de Desenvolvimento da Educação - PDE 2007 Traz como eixos a acessibilidade arquitetônica dos prédios escolares, a implantação de salas de recursos multifuncionais e a formação docente para o atendimento educacional especializado. 
O Decreto no 6.094/07 Estabelece dentre as diretrizes do Compromisso Todos pela Educação a garantia do acesso e permanência no ensino regular e o atendimento às necessidades educacionais especiais dos alunos, fortalecendo a inclusão educacional nas escolas públicas.

O Plano Nacional de Educação (PNE) 2011 Projeto de lei ainda em tramitação. A Meta 4 pretende "Universalizar, para a população de 4 a 17 anos, o atendimento escolar aos estudantes com deficiência, transtornos globais do desenvolvimento e altas habilidades ou superdotação na rede regular de ensino."

\section{DISCUSSÃO}

De acordo com os pressupostos legais, analisamos que, apesar de não ser recente a frequência da população em geral e de EPAEE nas escolas regulares, esse tema ganhou uma nova dimensão a partir da década de 1990, com a elaboração do Plano Decenal Para Todos 1993) e mais recentemente com a Resolução 02/01 e o Programa Educação Inclusiva: Direito a Diversidade (2003), que começou a ser implantado nas escolas brasileiras nos diferentes municípios do país, no ano de 2004.

Apesar da implantação de diferentes projetos e programas no Brasil, pouco se tem registrado a respeito do que pensam as pessoas que vivem esses processos, essa visão contribui para a ampliação do número de classes de aceleração em todo o país, especialmente estudantes \} com "dificuldades de aprendizagem".

Pensando na construção de uma escola inclusiva, as instituições de ensino devem garantir o acesso ao conhecimento, ou seja, deve-se pensar em ações, estratégias, projetos e espaços para propor para cada um de nossos estudantes a oportunidade de aprender. Mantoan (1997, p.120) explica que

[..] a inclusão é um motivo para que a escola se modernize e os professores aperfeiçoem suas práticas e, assim sendo, a inclusão escolar de pessoas deficientes torna-se uma consequência natural de todo um esforço de atualização e de reestruturação das condições atuais do ensino básico.

Portanto, podemos perceber que o Atendimento Educacional Especializado (AEE), na teoria e prática, deve ser inserido nas propostas inclusivas. Trata-se de atualizar o conhecimento sobre o assunto.

Discutir as razões da educação inclusiva em termos de benefícios para os estudantes, para os professores e para a sociedade contribui para o desenvolvimento de práticas que prepara os estudantes para a vida na comunidade, os professores melhoram suas habilidades profissionais e a sociedade torna-se consciente valorizando o ambiente social oferecendo oportunidades iguais para todas as pessoas.

Nesse contexto, a inclusão não se restringe apenas a escola, mas a qualquer lugar de convívio social. Por isso e necessário um trabalho conjunto entre a escola e a família, para que, juntas encontrem maneiras de construir espaços inclusivos para todos.

\section{CONCLUSÃO}

Apesar das dificuldades, as escolas devem atuar como mediadoras, auxiliando os EPAEE, seja nos casos de dificuldade motora geral ou acessibilidade, limitações motoras que necessitem de um período de adaptação, dificuldades comportamentais de estudantes agressivos que colocam em risco sua própria integridade, dificuldades de concentração e impulsividade de estudantes com TDAH, dificuldades de leitura, de comunicação e interação.

Nesses casos, a escola além de ser mediadora, deve contar com a Sala de Recursos Multifuncionais (SRM) para que os estudantes sejam atendidos de forma efetiva, a fim de melhorar a inclusão, diminuindo a exclusão das crianças com algum tipo de deficiência. 
A escola tem o papel de buscar alternativas educacionais, visando estar o mais próximo possível da realidade do aluno, em uma perspectiva de educação inclusiva com igualdade para a participação de todos.

Para isso, é importante identificar de que maneira o processo de ensinar e de aprender tem contribuído para a inclusão de EPAEE, considerando o papel fundamental que a escola e seus processos educacionais que devem ser seguidos através do currículo nacional escolar.

Essa realidade escolar requer professores especialistas que desenvolvam estratégias de ensino voltadas a todos os estudantes, mas também necessitam saber como intervir face às diferenças entre os estudantes de uma mesma turma, deve ser capaz de adequar as estratégias de ensino às dificuldades e potencialidades dos alunos.

As escolas devem atender as necessidades dos estudantes em todas as áreas do seu desenvolvimento. Assim, as escolas têm por finalidade rever planos e estratégias utilizadas pelo professor para avaliar todos os estudantes, verificando o grau de dificuldade e habilidade de cada um, descobrindo suas potencialidades, que precisam ser exploradas, para melhor desenvolvimento na aprendizagem.

\section{REFERÊNCIAS}

BAPTISTA, C. R.; BEYER, H. O. Inclusão e Escolarização: múltiplas perspectivas. Porto Alegre. Mediação, 2006.

BRASIL. Constituição (1988). Constituição da República Federativa do Brasil. Brasília, DF: Senado Federal, 1988.

BRASIL. Declaração Mundial sobre Educação para Todos: plano de ação para satisfazer as necessidades básicas de aprendizagem. UNESCO, Jomtiem/Tailândia, 1990.

BRASIL. Declaração de Salamanca e linha de ação sobre necessidades educativas especiais. Brasília: UNESCO, 1994.

BRASIL. Senado Federal. Lei de Diretrizes e Bases da Educação Nacional: no 9304/96. Brasília: 1996.

BRASIL: Ministério da Educação. Secretaria de Educação Especial. Política Nacional de Educação Especial na perspectiva da Educação Inclusiva. Brasília: MEC/SEESP, 2008.

CAMACHO, O. T. Atenção a Diversidade e Educação Especial. In: STOBAUS, C. D.; MOSQUERA, J. J. M. (Orgs.). Educação Especial: em direção à educação inclusiva. Porto Alegre: EDIPUCRS, 2003.

FIGUEIREDO, Rita Vieira. Políticas de inclusão: escola gestão da aprendizagem na diversidade. In: Políticas organizativas e curriculares, educação inclusiva e formação de professores. Rio de Janeiro: DP\&A, 2000.

MANTOAN, Maria Teresa Egler. Inclusão escolar de deficientes mentais: que formação para professores? In: MANTOAN, Maria Teresa Egler (org.) A integração de pessoas com deficiência: contribuições para uma reflexão sobre o tema. São Paulo: Memnon; SENAC, 1997.

OLIVEIRA, Maria Marly de: Como fazer pesquisa qualitativa. 2. ed. Petrópolis, RJ: Vozes, 2008 